\title{
Bilateral sternalis muscle in human fetus cadaver
}

\begin{abstract}
The sternalis muscle (SM), as known as rectus sterni, is an anomalous structure that lays at the anterior thoracic wall, which can be visualized as a unilateral or bilateral muscle. In this article, we report the existence of two SM's in a male fetus that aged 25 weeks. Despite the poor knowledge about proximal and distal attachments, vascularization and innervation of the SM, this structure can be the cause of different clinical implications. The presence of the SM can be wrongly interpreted by professionals as tumors at the anterior chest wall during mammographies and provoke electrical alterations at eletrocardiographies. The previous knowledge of the characteristics of the SM is crucial, as long as it allows professionals to correctly make the differential diagnosis between that muscle and benign or malign tumors at the anterior chest wall. In addition, since SM is known by surgeons, it can be used at breast reconstructive procedures.
\end{abstract}

Keywords: sternalis, anatomic variation, thoracic wall, reconstructive surgical procedures, muscles, skeletal, pectoralis major
Volume 6 Issue 4 - 2019

\author{
Lucas Dias Santos,' Lucas Oliveira Silva,' \\ Lúria Cardoso Bezerra,' José Aderval \\ Aragão 1,2 \\ 'Morphology Department, Federal University of Sergipe, \\ Aracaju, Sergipe, Brazil \\ ${ }^{2}$ Medical School of Tiradentes University (UNIT), Aracaju, \\ Sergipe, Brazil
}

Correspondence: José Aderval Aragão, Federal University of Sergipe, Marechal Rondon Avenue, São Cristóvão, Sergipe, Brazil, Tel+55-79-991916767 Email adervalufs@gmail.com

Received: June 22, 2019 | Published: July 22, 2019

\section{Introduction}

At the present time, the study of anatomical variations is seen as an important tool in medical practice, as long as it increases the assertiveness of diagnosis and the number of surgical possibilities. The SM, as known as "rectus sterni muscle", is considered a supernumerary structure ${ }^{1}$ located at the anterior and medial part of the thorax, near the pectoralis major muscle. ${ }^{2}$ The SM appears at about 3 to 8 per cent of global population, being unilateral in 2 to 8 per cent of the findings and having less prevalence of bilateral mode $(1.7 \%){ }^{3}$ The SM was registered for the first time by Barthelemy Cabrol at 1604 and described by Du Puy, 122 years later. ${ }^{4-6}$ The study of SM provides background for doctors and other health professionals to make the correct differential diagnosis between that muscle and tumors during mammographies. ${ }^{1,7}$ Furthermore, after being informed about the SM, surgeons can use it in reconstructive breast procedures. ${ }^{8,9}$ Therefore, our aim is to report the existence of a bilateral SM at an human fetus.

\section{Case report}

During routine dissection of a 25.7 weeks-old male fetus at the anatomy laboratory of the Federal University of Sergipe, Brazil, after superficial thoracic fascia removal, two SM (Figure 1) were identified at the anterior region of the thorax, over the pectoralis major muscle. The proximal attachments of both SM's were the sternal heads of the sternocleidomastoid muscles at both sides, next to the jugular notch. The distal attachments of the right SM were the fifth, sixth and seventh costal cartilages and costochondral junctions while those of the left SM were attached to the sixth, seventh and eighth costal cartilages and costochondral junctions. The morphometric data was organized at Table 1 .

Table I Morphometry of the sternalis muscles in millimeters

\begin{tabular}{lll}
\hline Dimension & \multicolumn{2}{l}{ Hemithorax } \\
\hline Width & Right & Left \\
\hline Proximal third & 4.02 & 3.72 \\
Middle third & 8.51 & 6.24 \\
Distal third & 7.70 & 6.11 \\
Length & 30.05 & 31.59 \\
\hline
\end{tabular}

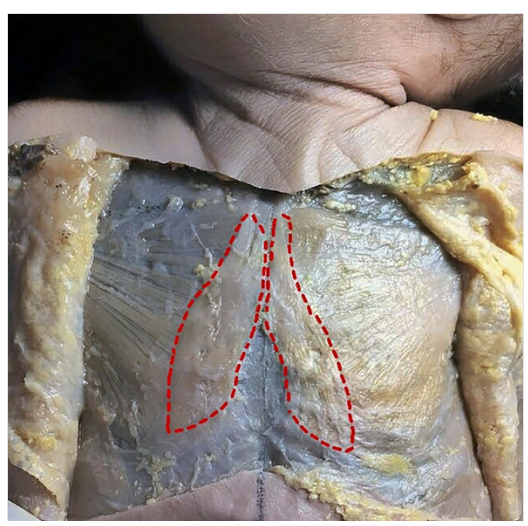

Figure I Anterior view of the dissected chest wall, with delimitation of the sternalis muscles.

\section{Discussion}

The embryonic origin of the SM is widely discussed, and the largest consensus is that the SM originates from adjacent muscles, such as the rectus abdominis, pectoralis major and sternocleidomastoid. ${ }^{10,11}$ Other authors even suggest that its origin can be differentiated by its innervation, which occurs either by the medial or lateral pectoral nerves $(51.9 \%)^{7}$ or intercostal nerves $(43.1 \%){ }^{11}$ There are also reports of SM innervation made by the cutaneous branches of anterior intercostal nerves. ${ }^{2}$ In our case, it was not possible to delimit such neural structures, event that was also reported by Raikos et at. ${ }^{8}$ and Sasmal et al. ${ }^{7}$ Furthermore, the SM vascularization is poorly reported, but some authors suggest that the blood supply is made by the branches of the internal thoracic artery., ${ }^{2} 12$

The SM is considered a rare variation, ${ }^{1,10,13}$ and it presents variable incidence between sexes ${ }^{10,14}$ and ethnic groups. For Bergman et al. ${ }^{15}$ the incidence rate is between $4 \%$ and $7 \%$ in white people, and about $8 \%$ in black and $11 \%$ in asians. ${ }^{4}$ The presence of the SM may be unilateral or bilateral, ${ }^{10}$ with the former being the most prevalent ${ }^{16}$ and, in some cases, up to two times its bilateral presence. ${ }^{15}$ In our case, the SM was also found bilaterally located in front of the pectoralis major muscle. 
Regarding the proximal attachment of the SM, we observed that it was in continuity with the tendon of the sternal head of the sternocleidomastoid muscle. This fact was also observed by several authors $7,8,10,11,17$ but variants have also been found as the proximal attachment of SM may be adherent to the pectoralis major fascia, ${ }^{8}$ to the aponeurosis of the external oblique muscle of the abdomen, ${ }^{8,17}$ to the manubrium sterni ${ }^{3,18,19}$ or to both sternal heads of sternocleidomastoid muscles, resulting in a y-shaped tendon. ${ }^{15}$ As to its distal attachment, it can be found both at the level of the xiphosternal joint in continuity with the sheath of the rectus abdominis muscle $e^{10,17}$ and in the aponeurosis of the external oblique muscle of the abdomen ${ }^{8,18}$ or in the 5 th to 7 th costal cartilages, ${ }^{1,6,8,19}$ which was also found in our study. In adults, the shape of the SM may be fusiform ${ }^{10,20,21}$ or peniform formation, ${ }^{8,10,18}$ which was found in our and other fetal dissections. ${ }^{3,22}$

The morphometry of the SM is quite variable in adults, and its length ranged from 100 to $230 \mathrm{~mm}$ on the right side and 135 to $260 \mathrm{~mm}$ on the left. In addition, its average width was $25 \mathrm{~mm}$ and $44 \mathrm{~mm}$ on right and left sides respectively.,6,10,18 These measures differed substantially from those in our findings, once our measurements were made on muscles of a 25 -week-old human fetus.

Although some authors have said that the SM has no function, there are evidences that its presence helps in the elevation of the lower portion of the pectoralis major, ${ }^{17,19}$ and also plays a secondary role in the elevation of the lower ribs..$^{15}$ Clinically, the presence of SM usually does not produce painful or touchable symptomatology, and its finding occurs during mammographies or surgeries. Since it is an accessory muscle in contraction, the SM can be confused with a hernia of the pectoralis major muscle, ${ }^{9}$ besides producing alterations in the electrical activities in electrocardiographic exams..$^{5,7}$ And, even its size being small and usually without any significant symptomatology, there are reports that show pain to the chest palpation..$^{23,24}$

The SM can be identified on imaging examinations, such as Magnetic Nuclear Resonance or Computed Tomography, as well as being visible by ultrasound. ${ }^{23}$ But still, it can be the cause of problem diagnosis on physical examination, being mistaken for lumps or tumors in mammograms. ${ }^{10,25}$ In addition, the SM can be a solution to cover and fix breast prostheses or to assist in reconstructive surgeries, such as fills after mastectomies or in the repair of muscular defects. ${ }^{7,16}$

\section{Conclusion}

The SM is a muscle variation of the anterior portion of thoracic wall that may be unilateral or bilateral, with variable insertions, morphologies and morphometries. Because it is rarely known by surgeons, radiologists and medical students, its description in anatomy books is very important for health professionals, helping in differentia diagnosis of breast tumors and in plastic and reconstructive surgeries.

\section{Funding}

None.

\section{Acknowledgements}

None.

\section{Conflicts of interest}

The authors declare there are no conflicts of interest.

\section{References}

1. Marques EF, Souza JA, Graziano L, et al. Músculo esternal simulando nódulo mamário. Rev Bras Ginecol Obstet. 2009;31(10):492-495.
2. Arraez LAA, Perez JS, Velasco JRM. Left musculus sternalis. Clin Anat. 2003;16(4):350-354.

3. Hung LY, Lucaciu OC, Wong JJ. Back to the debate: Sternalis Muscle. Int J Morphol. 2012;30(1):330-336.

4. Turner WM. On the Musculus Sternalis. J Anat Physiol. 1867;1(2):246253.

5. Michael S, Tubbs RS, Loukas M. Sternalis muscle, what every anatomist and clinician should know. Clin Anat. 2014;27(6):866-844.

6. Zaher WA, Darwish HH, Abdalla AME, et al. Sternalis: a clinically important variation. PakJ Med Sci. 2009;25(2):325-328.

7. Sasmal PK, Meher S, Mishra TS, et al. Sternalis Muscle: An Unexpected Finding during Mastectomy. Case Rep Surg. 2015;2015:723198.

8. Raikos A, Paraskevas GK, Tzika M, et al. Sternalis muscle: an underestimated anterior chest wall anatomical variant. $J$ Cardiothorac Surg. 2011;6:73.

9. Sari E, Oktemb HF, Durgunc M, et al. The sternalis muscle: an unusual anatomic finding during reconstruction of the soft tissue defect of mouth floor and neck, a case report. J Curr Surg. 2014;4(2):49-51.

10. O'neill MN, Curran JF. Bilateral sternalis muscles with a bilateral pectoralis major anomaly. J Anat. 1998;193(Pt 2):289-292.

11. Patten CJ. Right sternalis muscle with expanded fenestrated tendon. $J$ Anat. 1934;68(Pt 3):424-425.

12. Loukas M, Bowers M, Hullett J. Sternalis muscle: a mystery still. Folia Morphol. 2004;63(2):147-149.

13. Kida MY, Izumia TS. Sternalis muscles: topic for debate. Clin Anat. 2000;13(2):138-140.

14. Anjamrooz SH. Biceps sternalis: a Y-shaped muscle on the anterior chest wall. J Cardiothorac Surg. 2013;8:38.

15. Bergman RA, Afifi AK, Miyauchi R. Pectoralis Major and Pectoralis Minor. Illustrated encyclopaedia of human anatomic variation: Part I. University of Iowa. Virtual Hospital. 2001.

16. Khan UD. Use of the rectus sternalis in augmentation mammoplasty: case report and literature search. Aesthetic Plast Surg. 2008;32(1):21-24.

17. Cherian SB, Gandhalam AJ. Rectus sternalis muscle: An anatomical variant of anterior chest wall. OA Anatomy. 2014;2(2):16.

18. Kumar H, Rath G, Sharma M, et al. Bilateral sternalis with unusual left sided presentation: a clinical perspective. Yonsei Med J. 2003;44(4):719722 .

19. Jeng $\mathrm{H}, \mathrm{Su} \mathrm{SJ}$. The sternalis muscle: an uncommon anatomical variant among Taiwanese. J Anat. 1998;193(Pt 2):287-288.

20. Young Lee B, Young Byun J, Hee Kim H, et al. The Sternalis Muscles: incidence and imaging findings on MDCT. J Thorac Imaging. 2006;21(3):179-183.

21. Jelev L, Georgiev G, Surchev L. The Sternalis muscle in the Bulgarian population: classification of sternales. J Anat. 2001;199(Pt3):359-363.

22. Harper WF. The sternalis muscle in the anencephalous foetus. J Anat. 1936;70(Pt 2):317-320.

23. Scott-Conner CE, Al-Jurf AS. The sternalis muscle. Clin Anat. 2002;15(1):67-69.

24. Bradley FM, Hoover HC Jr, Hulka CA, et al. The sternalis muscle: an unusual normal finding seen on mammography. AJR Am J Roentgenol. 1996;166(1):33-36.

25. Gruber L, Martinoli C, Tagliafico AS, et al. A rare case of a symptomatic sternalis muscle: ultrasonograpy and MRI correlation. Ultrasound Int Open. 2016;2(4):140-141. 